Original Article

\title{
VALIDATED SPECTROPHOTOMETRIC METHOD FOR THE ESTIMATION OF VINCRISTINE AND VINBLASTINE
}

\author{
HALAHAKOON AMILA JEEWANTHA*, SLIVKIN ALEKSEI IVANOVICH, KARLOV PAVEL MIHAILOVICH
}

Department of Pharmaceutical Chemistry and Pharmaceutical Technology, Voronezh State University, 394620, Street Studencheskya 3, Voronezh, Russia

Email: amilajh1982@hotmail.com

Received: 13 Dec 2016 Revised and Accepted: 14 Feb 2017

\section{ABSTRACT}

Objective: A simple, sensitive, precise, reproducible and validated UV spectrophotometric methods have been developed for the determination of vincristine (VCR) and vinblastine (VLB) in the pure and dosage forms.

Methods: The method was founded on the simple solubility of VCR and VLB in purified water, and their characteristic maximum absorption $\lambda_{(\max )}$ at $295 \mathrm{~nm}$ and $\lambda_{(\max )}$ at $268 \mathrm{~nm}$ for VCR and VLB respectively in the UV regions. The nature of obedience, to the Bouguer-Lambert-Beer's law by the VCR and VLB in the range of concentration $5-50 \mu \mathrm{g} / \mathrm{ml}$ was employed to this method.

Results: Accuracy and reproducibility of the proposed method were statistically validated by recovery studies. The accuracy of the method for the VCR and VLB was $\sim 100.4 \%$ and $\sim 100.32 \%$ respectively with good reproducibility. The analytical curves were linear over a wide concentration range $(5-50 \mu \mathrm{g} / \mathrm{ml})$, with a correlation coefficient (r)-0.9998, and 0.9999 for VCR and VLB in that order. The method was showed sufficient precision, with a relative standard deviation (RSD) less than $1 \%$.

Conclusion: The method was validated in accordance with Russian general pharmacopoeia article (RGPA) 42-0113-09 and ICH guidelines. Validated method can easily apply for fast, precise and reliable rapid assessment of drug forms and pure substances in the laboratory.

Keywords: Vincristine, Vinblastine, Analytical curve, Quantity determination, UV-visible spectrometry

(C) 2017 The Authors. Published by Innovare Academic Sciences Pvt Ltd. This is an open access article under the CC BY license (http://creativecommons.org/licenses/by/4.0/) DOI: http://dx.doi.org/10.22159/ijpps.2017v9i4.16577

\section{INTRODUCTION}

Catharanthus roseus (L.) G. Don (C. roseus) is a tropical plant, which belongs to the family of Apocynaceae. Vincristine and vinblastine are known, highly valuable terpenoid indole alkaloids (TIAs) from over 130 alkaloids, which were found in C. roseus. Dimeric TIA VCR has been widely used as an antitumor agent since the 1960s [1-8]. C. roseus has been used in traditional medicine in tropical and subtropical countries for the treatment of diabetes, hypertension, bleeding, scurvy, toothaches, and others from ancient time. [7] At the moment in vivo and in-vitro studies have demonstrated hypoglycemic, antihypertensive, anti-bacterial, anti-malarial, antiarrhythmic and other properties of $C$. roseus [9-14].

The alkaloids can produce specific color reactions with various chemical reagents, some colorimetric methods for identification of TIAs were reported, as an example: VLB with 1\% ferric ammonium sulfate solution and $75 \%$ sulfuric acids mixture, was formed a dark bluish color. But those color reactions cannot use as the evidence for identification and characterize TIAs from other alkaloids types (tropane, quinolone, purine, etc.) and only indicating the presence of some alkaloids or amines derivatives [15].

The chemical structures of TIAs (fig.1) have chromophores and auxochromes groups, which were responsible for the appearance of the specific peaks in the absorption spectrum in the UV range. Usually, chromophores defined as unsaturated or aromatic units of molecules. Chemically pure VCR and VLB sulfates have characteristic absorption peaks in the UV spectrum. VCR sulfate have three characteristic peaks $\lambda_{\text {(max) }}-(222,256,298) \pm 2 \mathrm{~nm}[16$ $18]$ and VLB sulfate has two characteristic peaks $\lambda$ (max)- $(214$, 266) $\pm 2 \mathrm{~nm}$ [16-18] in the UV absorption spectrum in methanol. American (USP), British (B. Ph.), European (E. Ph.), Japanese (J. Ph. $\mathrm{XVI}$ ) and International (Int. Ph.) Pharmacopeias have recommendations to use UV, and IR specter characterizes of chemically pure VCR, and VLB sulfates for identification and standardizations drugs contains those compounds.
Nowadays for the quantitative analysis of the terpenoid indole drugs usually appropriate methods are high performance liquid chromatography (HPLC) [19-21] (recommended method for VCR and VLB-E. Ph.7.0;J. Ph. XVI; B. Ph.2013;USP; Int. Ph.) and its variations like, HPLC-UV-detector $[19,21,22]$, HPLC-with electrochemical detector [23-24], HPLC-isotope dilution thermospray mass spectrometry [25], and also methods like thin layer chromatography $[7,19,26]$, liquid chromatography with mass spectral detection $[21,27,28]$, capillary zone electrophoresis-mass spectrometry [20], capillary electrophoresis-mass spectrometry [11, 29], radio-immune analysis [30,31] etc. Many of these methods are characterized by highly labor intensive, the high cost of equipment's, long duration of analysis time, as well as usually highly toxic chemicals, are required for an analysis procedure. Most spread commonly prefer analytical method in the most of the laboratories in these days, is HPLC, but all around high-cost outcome for one analysis avoid it from regular usage. The aim of this work was dedicated to producing validated a simple and affordable spectrophotometric method for evaluating the quality of drug VCR and VLB in pure substances, dosage formulations and the biological materials after pretreatments.

\section{MATERIALS AND METHODS}

Pharmaceutical formulations

Vinblastine-LANS ${ }^{\circledR}$ (LENS-Pharm Russia),vincristine-TEVA (Teva Pharmaceutical Industries Ltd., Israel), VERO-vincristine (LENSPharm Russia), vincristine-Richter (Gedeon Richter Ltd., Hungary) are meet al. l requirements of the current regulatory documentations in Russia, were purchased from the domestic market in Voronezh city.

\section{Materials and reagents}

All chemicals and reagents were of analytical grade and used without further purification, and all solutions were prepared fresh daily. Water has been purified using the medical water distillation 
apparatus AE-25 (Tumenmed, Russia). Analytical experiments were performed on a Hitachi ratio beam spectrophotometer U-1900 (Japan), data processing carried out using software packages, Microsoft Excel, StatSoft Statistica and Origin pro-2015.

\section{Preparation of stock standard solution}

As a result of low availability and the high cost of standard samples of VCR and VLB sulfates in the domestic market, in the experimental work, was used commercial dosage forms of these substances. Standard solution of VCR sulfate (solution A) was prepared using vincristine-TEVA $1.0 \mu \mathrm{g} / \mathrm{ml}$, contain in the composition of $1.0 \mathrm{ml}$ solution: active substance $1.0 \mathrm{mg}$ VCR sulfate (calculated as anhydrous substance), as adjuvant-mannitol, sodium hydroxide, sulfuric acid and aqua pro injectionibus and vincristine-Richter lyophilisate $1.0 \mathrm{mg}$, in the composition, contain: active substance $100 \%$ pure VCR sulfate $1.0 \mathrm{mg}$, lactose as excipient. To prepare standard solutions (solution A) of VCR and VLB sulfates were used vincristine-Richter lyophilisate and vinblastine-LANS ${ }^{\circledR}$ lyophilisate, in composition contain $100 \%$ pure VCR and VLB.

VCR solution A (stock solution)-vincristine-Richter lyophilisate, a dosage of $1.0 \mathrm{mg}$ five ampules, were accurately transferred into 50 $\mathrm{ml}$ volumetric flask separately and diluted with purified water to nominal volume, at the final solution concentration was $100 \mu \mathrm{g} / \mathrm{ml}$.

VLB solution A (stock solution)-vinblastine-LANS ${ }^{\circledR}$ lyophilisate 5.0 mg was carefully transferred into $50 \mathrm{ml}$ volumetric flask and diluted with purified water to the nominal volume, at the final solution concentration was $100 \mu \mathrm{g} / \mathrm{ml}$. The standard solutions were found stable for at least one week without alteration when kept in an amber colored bottle and stored at $4{ }^{\circ} \mathrm{C}$ in the refrigerator when not in use.

\section{General procedures}

For the quantitative analysis of VCR and VLB, was applied analytical curve method $[4,16]$, constructed on the base of standard solutions series $(\mathrm{n}-10)$ with a concentration range of $5-50 \mu \mathrm{g} / \mathrm{ml}$. A series of standard solutions samples $(n-10)$ were prepared: from the standard solution A, was taken aliquot volume $0.5 \mathrm{ml}, 1.0 \mathrm{ml}, 1.5 \mathrm{ml}$, $2.0 \mathrm{ml}, 2.5 \mathrm{ml}, 3.0 \mathrm{ml}, 3.5 \mathrm{ml}, 4.0 \mathrm{ml}, 4.5 \mathrm{ml}$ and $5.0 \mathrm{ml}$, then diluted to $10 \mathrm{ml}$ volume with purified water. Accordingly received standard sample solutions with concentration $5 \mu \mathrm{g} / \mathrm{ml}, 10 \mu \mathrm{g} / \mathrm{ml}, 15 \mu \mathrm{g} / \mathrm{ml}$, $20 \mu \mathrm{g} / \mathrm{ml}, 25 \mu \mathrm{g} / \mathrm{ml}, 30 \mu \mathrm{g} / \mathrm{ml}, 35 \mu \mathrm{g} / \mathrm{ml}, 40 \mu \mathrm{g} / \mathrm{ml}, 45 \mu \mathrm{g} / \mathrm{ml}$ and 50 $\mu \mathrm{g} / \mathrm{ml}$ respectively.

UV absorption spectrum of all samples of VCR and VLB sulfate were recorded over the wavelength range $\lambda-400 \mathrm{~nm}$ to $190 \mathrm{~nm}$, at room temperature $\left(20^{\circ} \mathrm{C}\right)$ using $10 \mathrm{~mm}$ quartz cell at Hitachi ratio beam spectrophotometer U-1900.

\section{RESULTS}

The aqueous solution of VCR sulfate has maximum absorption peak $\lambda_{(\max )}$ at $295 \mathrm{~nm} \pm 1 \mathrm{~nm}, 254 \mathrm{~nm} \pm 1 \mathrm{~nm}$ and $219 \pm 1 \mathrm{~nm}$, and VLB sulfate has $\lambda_{(\max )}$ at $268 \mathrm{~nm} \pm 1 \mathrm{~nm}$ and $219 \mathrm{~nm} \pm 1 \mathrm{~nm}$, respectively (fig. 2, fig. 3).

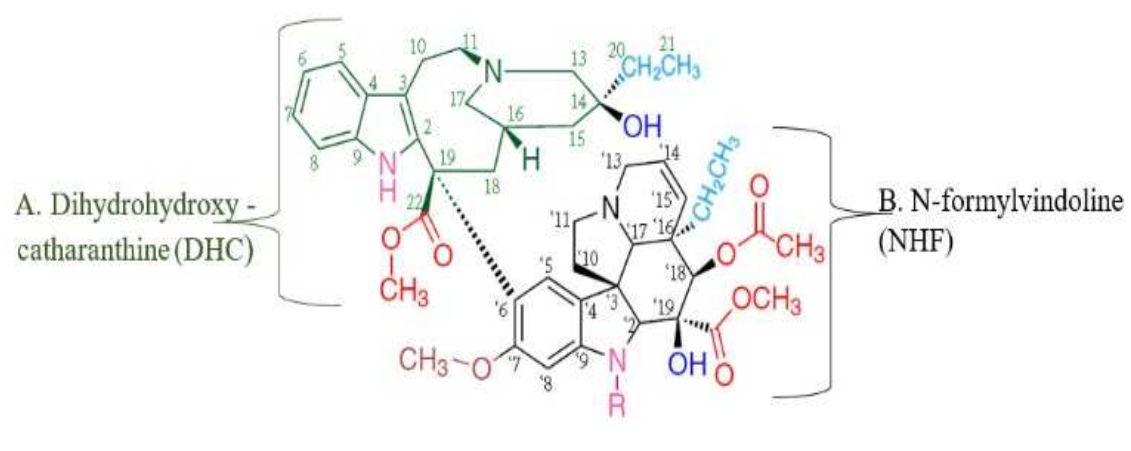

R-CHO-VCR, R-CH3-VLB

Fig. 1: The chemical structure of VCR and VLB*, A. Catharanthine fragment (indole fragment), B. Vindoline fragment (indoline fragments) *The chemical structure was sketched in accordance with information in the references: $[2,16,17]$

The analytical range was selected, by analyzing the concentration of samples, the absorption values (Abs) were in the range of $0.1 \sim 1.0$ at the chosen $\lambda_{(\max )} 295 \mathrm{~nm}, 268 \mathrm{~nm}$ for VCR and VLB respectively. Theoretically, in this range, VCR and VLB concentration and absorption characters must have subjected to the Bouger-Lambert-Beer's law with the least error. For the analytical range determination study, was prepared a series of standard solutions with concentration $250 \mu \mathrm{g} / \mathrm{ml}, 100 \mu \mathrm{g} / \mathrm{ml}, 50$ $\mu \mathrm{g} / \mathrm{ml}, 20 \mu \mathrm{g} / \mathrm{ml}, 10 \mu \mathrm{g} / \mathrm{ml}, 5 \mu \mathrm{g} / \mathrm{ml}, 1 \mu \mathrm{g} / \mathrm{ml}$ respectively. The experimental data were presented in the table. 1 . In the results can identify the optimal concentration range for an analytical procedure was $5-50 \mu \mathrm{g} / \mathrm{ml}$.

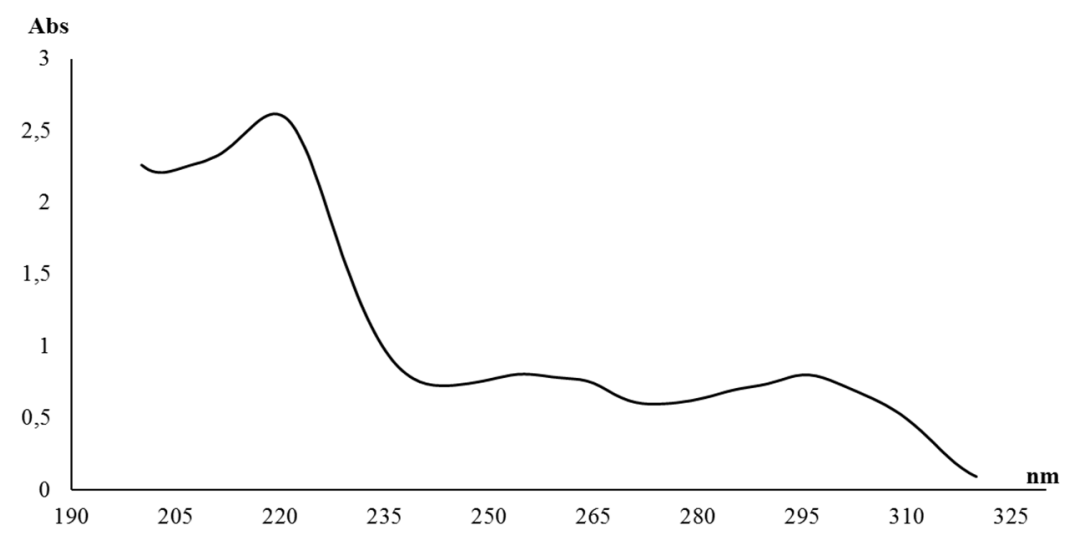

Fig. 2: UV absorption spectrum of VCR sulfate $40 \mu \mathrm{g} / \mathrm{ml}$ aqueous solution 


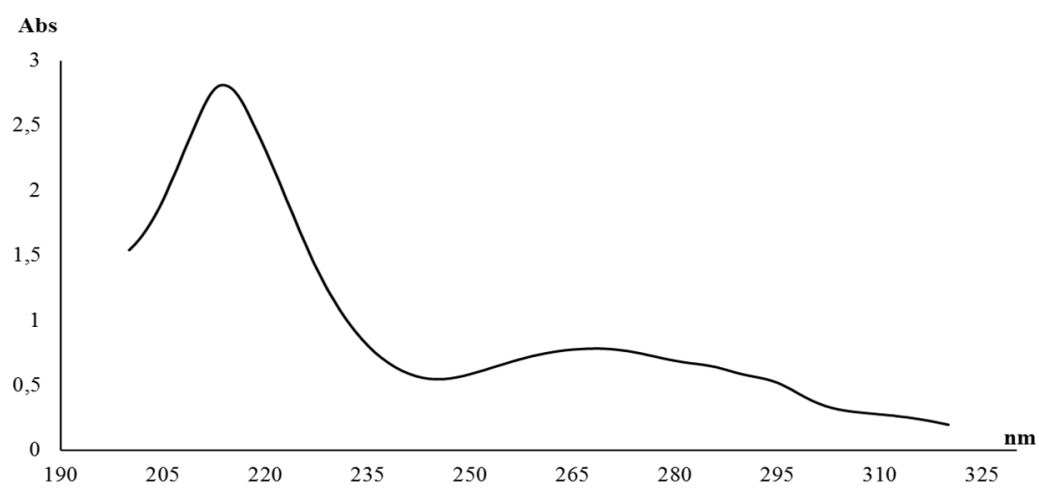

Fig. 3: UV absorption spectrum of VLB sulfate $40 \mu \mathrm{g} / \mathrm{ml}$ aqueous solution

Table 1: The absorption value of VCR and VLB solutions in the analytical range

\begin{tabular}{lll}
\hline Solution conc. $(\mu \mathrm{g} / \mathbf{m l})$ & VCR sulfate Abs $\boldsymbol{\lambda}_{295} \mathbf{~ m m}$ & VLB sulfate Abs $\lambda_{268} \mathbf{~ m}$ \\
\hline 250 & $3.253 \pm 0.004$ & $3.268 \pm 0.003$ \\
100 & $1.568 \pm 0.003$ & $1.859 \pm 0.002$ \\
50 & $0.987 \pm 0.002$ & $0.970 \pm 0.002$ \\
20 & $0.400 \pm 0.001$ & $0.398 \pm 0.001$ \\
10 & $0.274 \pm 0.001$ & $0.202 \pm 0.001$ \\
5 & $0.104 \pm 0.001$ & $0.102 \pm 0.001$ \\
1 & $0.038 \pm 0.002$ & $0.039 \pm 0.002$ \\
\hline
\end{tabular}

*Total amount of samples (n)-21, All Abs values represent mean \pm SD

The absorbance values of standard samples were registered using Hitachi ratio beam spectrophotometer U-1900, in $10 \mathrm{~mm}$ quartz cells at the room temperature $\left(20^{\circ} \mathrm{C}\right)$ with a scanning speed of $400 \mathrm{~nm} / \mathrm{min}$, a sampling interval of $0.5 \mathrm{~nm}$ and sensitivity value 1 with a 0.01 threshold. The maximum absorption (Abs) values of standard samples (5-50 $\mu \mathrm{g} / \mathrm{ml}) \mathrm{VCR}$ sulfate at wavelength $\lambda_{(\max )} 295 \mathrm{~nm}$ and VLB sulfate $\lambda_{(\max )} 268$ nm were shown in table 2 .

Table 2: Absorption values of the VCR and VLB sulfates standard solutions

\begin{tabular}{|c|c|c|c|c|}
\hline \multirow[t]{2}{*}{ Sample series №* } & \multicolumn{2}{|l|}{ VLB sulfate } & \multicolumn{2}{|l|}{ VCR sulfate } \\
\hline & Con. $(\mu \mathrm{g} / \mathrm{ml})$ & AbS $\lambda(\max ) 268 \mathrm{~nm}$ & Con. $(\mu \mathrm{g} / \mathrm{ml})$ & $\operatorname{Abs}_{\lambda(\max ) 295 \mathrm{~nm}}$ \\
\hline 1 & 5 & $0.105 \pm 0.001$ & 5 & $0.109 \pm 0.002$ \\
\hline 2 & 10 & $0.200 \pm 0.001$ & 10 & $0.208 \pm 0.001$ \\
\hline 3 & 15 & $0.298 \pm 0.001$ & 15 & $0.304 \pm 0.001$ \\
\hline 4 & 20 & $0.403 \pm 0.001$ & 20 & $0.405 \pm 0.001$ \\
\hline 5 & 25 & $0.498 \pm 0.001$ & 25 & $0.502 \pm 0.001$ \\
\hline 6 & 30 & $0.593 \pm 0.001$ & 30 & $0.588 \pm 0.002$ \\
\hline 7 & 35 & $0.681 \pm 0.001$ & 35 & $0.694 \pm 0.001$ \\
\hline 8 & 40 & $0.782 \pm 0.002$ & 40 & $0.803 \pm 0.002$ \\
\hline 9 & 45 & $0.874 \pm 0.004$ & 45 & $0.893 \pm 0.001$ \\
\hline 10 & 50 & $0.971 \pm 0.002$ & 50 & $0.984 \pm 0.005$ \\
\hline
\end{tabular}

*Total amount of samples (n)-30, All Abs values represent mean \pm SD

The calibration curves were constructed by plotting absorbance vs. concentration of VCR and VLB standard samples. The parameters of calibration curves of the VCR and VLB were shown in table 3. Linear regression was calculated based on the obtaining experimental data using the software package, Microsoft Excel and Origin Pro 2015.

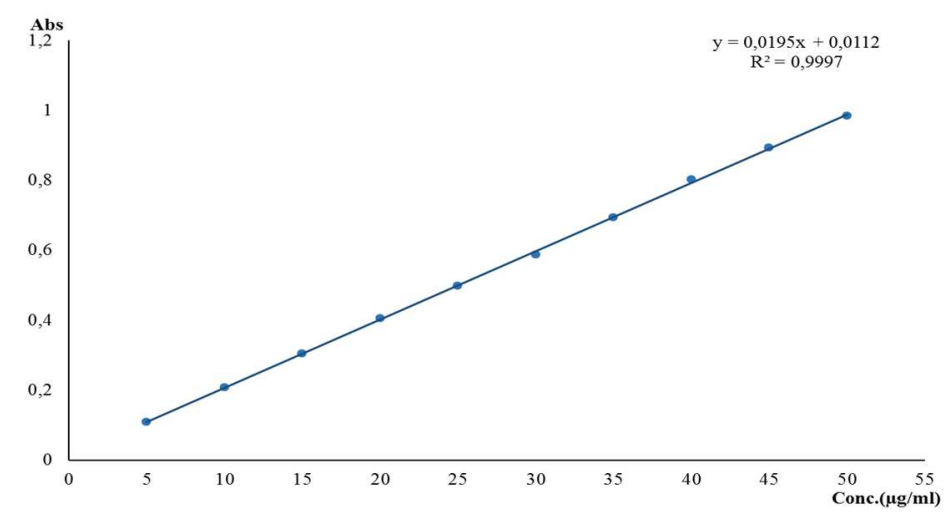

Fig. 4: Calibration graph of VCR sulfate 


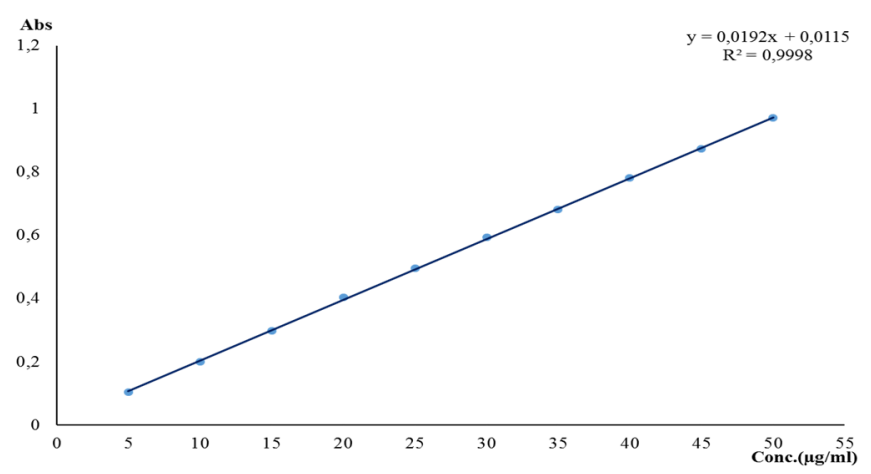

Fig. 5: Calibration graph of VLB sulfate

Table 3: Parameters of the regression equation of VCR and VLB

\begin{tabular}{lll}
\hline Parameters & VCR sulfate & VLB sulfate \\
\hline Slope & 0.01954 & 0.01923 \\
Intercept & 0.01120 & 0.01153 \\
Linear regression & $\mathrm{y}=0.0195 \mathrm{x}+0.0112$ & $\mathrm{y}=0.0192 \mathrm{x}+0.0115$ \\
Correlation coefficient $(\mathrm{r})$ & 0.99985 & 0.99991 \\
Coefficient of determination ${ }^{2}$ & 0.99971 & 0.99978 \\
SD & 0.00538 & 0.00438 \\
Limit of quantification $(\mu \mathrm{g} / \mathrm{ml})$ & 6.389 & 6.126 \\
Limit of detection $(\mu \mathrm{g} / \mathrm{ml})$ & 2.108 & 2.022 \\
\hline
\end{tabular}

Validation procedure of the analytical method was performed, according to the requirements of general pharmacopeia article 420113-09 (12 $2^{\text {th }}$ State Pharmacopoeia Russian Federation) and ICH guidelines, by following criteria: specificity, linearity, precision, accuracy, limit of detection, limit of quantification, and stability (robustness) of the analytical method [32, 33].

\section{The precision and accuracy determination}

Three different concentrations in the range of $5-50 \mu \mathrm{g} / \mathrm{ml}$, was selected for the experiment as sample standard solutions, one of them belong to the lower level $10 \mu \mathrm{g} / \mathrm{ml}$, middle level $25 \mu \mathrm{g} / \mathrm{ml}$, and higher level $40 \mu \mathrm{g} / \mathrm{ml}$. Measurements were carried out as follows: in each one of the three levels were contain nine different samples (total amount of 27 samples),on three different days, all the analyzed solutions were prepared in the same conditions, from the freshly prepared stock solutions each day, as a result of the absorption measurements of 27 samples, the median values were found for the each series.

The results were presented in tables 4 and 5 respectively. The accuracy was determined by adding standard amounts of VCR and VLB into $50 \mu \mathrm{g} / \mathrm{ml}, 125 \mu \mathrm{g} / \mathrm{ml}$, and $250 \mu \mathrm{g} / \mathrm{ml}$ sample solutions, after that final solutions absorption values were measured and found a median value for each sample. The results were shown in table 6 and 7 in that order.

Table 4: The experimental data of the precision (VCR sulfate)

\begin{tabular}{|c|c|c|c|c|c|c|}
\hline $\begin{array}{l}\text { Sample } \\
\text { Series No.* }\end{array}$ & $\begin{array}{l}\text { Theoretical con. of } \\
\text { samples }(\mu \mathrm{g} / \mathrm{ml})\end{array}$ & $\begin{array}{l}\text { Determined concentration of } \\
\text { samples }(\mu \mathrm{g} / \mathrm{ml})\end{array}$ & R (\%) & $\mathbf{R}(\%)_{\text {(mean) }}$ & SD & RSD \\
\hline 1 & 10 & $10.30 \pm 0.089$ & 103.53 & & & \\
\hline 2 & 10 & $9.81 \pm 0.059$ & 98.10 & 100.08 & 0.5233 & 0.5299 \\
\hline 3 & 10 & $9.79 \pm 0.051$ & 97.90 & & & \\
\hline 4 & 25 & $24.75 \pm 0.030$ & 99.01 & & & \\
\hline 5 & 25 & $26.05 \pm 0.029$ & 104.2 & & & \\
\hline 6 & 25 & $24.79 \pm 0.051$ & 99.16 & & & \\
\hline 7 & 40 & $39.30 \pm 0.078$ & 98.25 & & & \\
\hline 8 & 40 & $41.13 \pm 0.078$ & 102.83 & & & \\
\hline 9 & 40 & $39.10 \pm 0.078$ & 97.75 & & & \\
\hline
\end{tabular}

*Total amount of samples (n)-27, All Abs values represent mean \pm SD

Table 5: The experimental data of the precision (VLB sulfate)

\begin{tabular}{|c|c|c|c|c|c|c|}
\hline $\begin{array}{l}\text { Sample } \\
\text { Series No.* }\end{array}$ & $\begin{array}{l}\text { Theoretical conc. of } \\
\text { samples }(\mu \mathrm{g} / \mathrm{ml})\end{array}$ & $\begin{array}{l}\text { Determined conc. of } \\
\text { samples }(\mu \mathrm{g} / \mathrm{ml})\end{array}$ & R (\%) & $\mathbf{R}(\%)_{\text {(mean) }}$ & SD & RSD \\
\hline 1 & 10 & $10.13 \pm 0.06$ & 103.53 & & & \\
\hline 2 & 10 & $10.15 \pm 0.08$ & 98.10 & 100.17 & 0.9271 & 0.9255 \\
\hline 3 & 10 & $10.15 \pm 0.08$ & 97.90 & & & \\
\hline 4 & 25 & $25.02 \pm 0.03$ & 99.01 & & & \\
\hline 5 & 25 & $25.13 \pm 0.08$ & 104.2 & & & \\
\hline 6 & 25 & $25.06 \pm 0.12$ & 99.16 & & & \\
\hline 7 & 40 & $39.60 \pm 0.10$ & 98.25 & & & \\
\hline 8 & 40 & $39.69 \pm 0.03$ & 102.83 & & & \\
\hline 9 & 40 & $39.90 \pm 0.06$ & 97.75 & & & \\
\hline
\end{tabular}

*Total amount of samples (n)-27, All values represent mean \pm SD 
Table 6: Experimental data of determining the accuracy of the analytical method (VLB sulfate)

\begin{tabular}{|c|c|c|c|c|c|c|c|c|}
\hline $\begin{array}{l}\text { Sample } \\
\text { Series } \\
\text { No.* }\end{array}$ & $\begin{array}{l}\text { Amount of } \\
\text { sample taken- } \\
\mathbf{m}^{* *}(\mu \mathrm{g})\end{array}$ & $\begin{array}{l}\text { Amount of } \\
\text { Standard added } \\
M^{* *}(\mu \mathrm{g})\end{array}$ & $\begin{array}{l}\text { Abs value } \\
\text { of the final } \\
\text { solution }(\mathrm{m}+\mathrm{M})\end{array}$ & $\begin{array}{l}\text { Found } \\
\text { amount } \\
(\mu \mathrm{g})\end{array}$ & $\begin{array}{l}\text { Found } \\
\text { amount } \\
(\%)\end{array}$ & $\mathrm{R} \%$ (mean) & SD & RSD \\
\hline 1 & 50 & 200 & $0.491 \pm 0.001$ & 249.36 & 99.74 & & & \\
\hline 2 & 50 & 200 & $0.492 \pm 0.001$ & 249.88 & 99.95 & 100.32 & 0.1080 & 0.1077 \\
\hline 3 & 125 & 200 & $0.65 \pm 0.002$ & 332.053 & 102.17 & & & \\
\hline 4 & 125 & 200 & $0.65 \pm 0.002$ & 332.053 & 102.17 & & & \\
\hline 5 & 250 & 50 & $0.589 \pm 0.002$ & 300.328 & 100.11 & & & \\
\hline 6 & 250 & 50 & $0.587 \pm 0.002$ & 299.288 & 99.76 & & & \\
\hline 7 & 250 & 200 & $0.871 \pm 0.002$ & 446.99 & 99.33 & & & \\
\hline 8 & 250 & 200 & $0.871 \pm 0.002$ & 446.99 & 99.33 & & & \\
\hline
\end{tabular}

*Total amount of samples (n)-24, All Abs values represent mean \pm SD, ** Quantity of VCR and VLB in the sample-m $(\mu \mathrm{g})$ and M $(\mu \mathrm{g})$, was calculated according to $100 \mu \mathrm{g} / \mathrm{ml}$ standard stock aqueous solution.

Table 7: Experimental data of determining the accuracy of the analytical method (VCR sulfate)

\begin{tabular}{|c|c|c|c|c|c|c|c|c|}
\hline $\begin{array}{l}\text { Sample } \\
\text { Series } \\
\text { No.* }\end{array}$ & $\begin{array}{l}\text { Amount of } \\
\text { sample taken- } \\
\mathrm{m}^{* *}(\mu \mathrm{g})\end{array}$ & $\begin{array}{l}\text { Amount of } \\
\text { standard added } \\
M^{* *}(\mu \mathrm{g})\end{array}$ & $\begin{array}{l}\text { Abs of the final } \\
\text { solution }(m+M)\end{array}$ & $\begin{array}{l}\text { Found amount } \\
(\mu \mathrm{g})\end{array}$ & $\begin{array}{l}\text { Found amount } \\
(\%)\end{array}$ & R\%(mean) & SD & RSD \\
\hline 1 & 50 & 200 & $0.501 \pm 0.002$ & 250.642 & 100.257 & & & \\
\hline 2 & 50 & 200 & $0.503 \pm 0.001$ & 251.656 & 100.666 & 100.14 & 0.1485 & 0.1483 \\
\hline 3 & 125 & 200 & $0.646 \pm 0.003$ & 324.842 & 99.951 & & & \\
\hline 4 & 125 & 200 & $0.648 \pm 0.002$ & 325.865 & 100.266 & & & \\
\hline 5 & 250 & 50 & $0.598 \pm 0.002$ & 300.279 & 100.093 & & & \\
\hline 6 & 250 & 50 & $0.597 \pm 0.001$ & 299.767 & 99.922 & & & \\
\hline 7 & 250 & 200 & $0.891 \pm 0.002$ & 450.214 & 100.05 & & & \\
\hline 8 & 250 & 200 & $0.890 \pm 0.002$ & 449.702 & 99.934 & & & \\
\hline
\end{tabular}

*Total amount of samples (n)-24, All Abs values represent mean \pm SD, ** Quantity of VCR and VLB in the sample-m $(\mu \mathrm{g})$ and M $(\mu \mathrm{g})$, was calculated according to $100 \mu \mathrm{g} / \mathrm{ml}$ standard stock aqueous solution.

\section{Sensitivity}

The limit of detection (LOD) has been established in compliance with the general pharmacopoeia article 42-0113-09. The detection limit for VCR and VLB were calculated according to the equalization of the calibration curve. The theoretical value of the LOD was experimentally confirmed using VCR sulfate, and VLB sulfate sample solutions which were solution concentration related to $1 \mu \mathrm{g} / \mathrm{ml}$.

The results were presented in the table. 8.

Table 8: Limit of detection parameters of VCR and VLB

\begin{tabular}{lllll}
\hline Substance & $\begin{array}{l}\text { Concentration of sample } \\
\text { solution }(\boldsymbol{\mu g} / \mathbf{m l})\end{array}$ & $\begin{array}{l}\text { Absorption } \\
\text { value }\end{array}$ & $\begin{array}{l}\text { Theoretical limit of detection } \\
(\boldsymbol{\mu g} / \mathbf{m l})\end{array}$ & $\begin{array}{l}\text { Experimentally stablished limit of } \\
\mathbf{d e t e c t i o n} \text { by linear regression }(\boldsymbol{\mu g} / \mathbf{m l})\end{array}$ \\
\hline VCR sulfate & 1.0 & $0.039 \pm 0.002$ & 2.1081 & 1.4226 \\
VLB sulfate & 1.0 & $0.035 \pm 0.001$ & 2.0219 & 1.2205 \\
\hline
\end{tabular}

*Total amount of samples (n)-6, All Abs values represent mean \pm SD

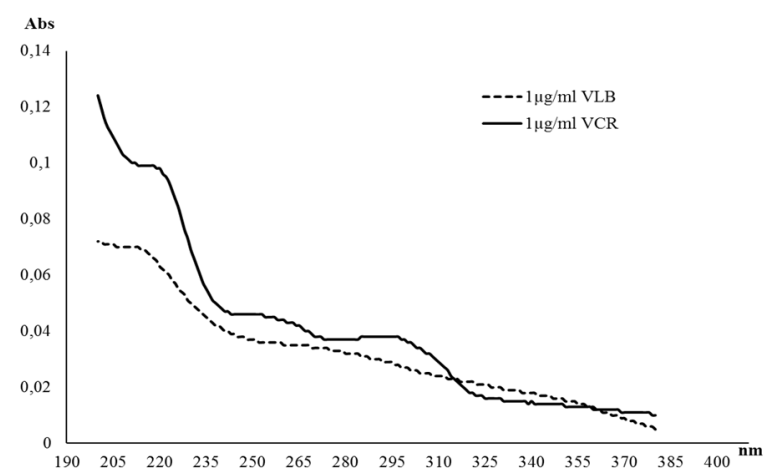

Fig. 6: The detection limit VCR and VLB sulfate aqueous solution

\section{The robustness determination}

The polarity of the solvent and the $\mathrm{pH}$ of the medium may affect the electron transition of the molecules during energy absorption from the electromagnetic wave. For example, the polarity of the solvent can affect the $\pi \rightarrow \pi *$ transition (excited level), $n \rightarrow \pi *$ transitions, in an acidic medium can disappear [34]. It is, therefore, necessary to establish the optimal conditions for an analytical method under the criteria: the medium $\mathrm{pH}$ and the solvent polarity.

When determining an optimal $\mathrm{pH}$ environment for the analytical method, were used different buffer solutions, in the pH range of 3 to 10 .

Series of buffer solutions $\mathrm{pH}$ 3-10 were prepared by following the Russian general pharmacopoeial article 42-0072-02. The $\mathrm{pH}$ of each solution was adjusted to an appropriate value using the $\mathrm{pH}$ meter with accordance to the pharmacopoeial article. Freshly prepared solutions were always employed.

For determination of the robustness prepared series of $25 \mu \mathrm{g} / \mathrm{ml}$ standard solutions VCR and VLB, as the solvent used buffer solutions in range $\mathrm{pH} 3$ to $\mathrm{pH} 10 . \mathrm{pH}$ of the purified water and all the buffer solutions was measured at room temperature $\left(20^{\circ} \mathrm{C}\right)$ using a $\mathrm{pH}$ meter model, pH-121(Russia). The maximum absorption $\lambda_{\text {(max) }}$ values of VCR and VLB $25 \mu \mathrm{g} / \mathrm{ml}$ standard solutions were shown in table 10 and the graphical demonstration in fig. 7. 
Table 9: Variation of $\lambda_{(\max )} V C R$ with different solvents

\begin{tabular}{|c|c|c|c|c|c|c|}
\hline Type of solvent & $\begin{array}{l}\text { Concentration of solution } \\
\operatorname{VCR}(\mu \mathrm{g} / \mathrm{ml})\end{array}$ & $\begin{array}{l}\text { VCR } \lambda_{(\max )} \\
(\mathrm{nm})\end{array}$ & $\begin{array}{l}\text { Absorption } \\
\text { value } A b s \text { (VCR) }\end{array}$ & $\begin{array}{l}\text { Concentration of } \\
\text { solution VLB }(\mu \mathrm{g} / \mathrm{ml})\end{array}$ & $\begin{array}{l}\text { VLB } \lambda_{(\max )} \\
(\mathrm{nm})\end{array}$ & $\begin{array}{l}\text { Absorption } \\
\text { value Abs (VLB) }\end{array}$ \\
\hline Purified water & 10 & 295 & $0.263 \pm 0.001$ & 40 & 268 & $0.628 \pm 0.001$ \\
\hline $0.1 \mathrm{~mol} \mathrm{HCl}$ & 10 & 296 & $0.300 \pm 0.001$ & 40 & 268.5 & $0.544 \pm 0.001$ \\
\hline $0.1 \mathrm{~mol} \mathrm{NaOH}$ & 10 & 298 & $0.251 \pm 0.001$ & 40 & 267 & $0.538 \pm 0.001$ \\
\hline
\end{tabular}

*Total amount of samples (n)-9, All Abs values represent mean \pm SD

Table 10: Variation of $\lambda_{(\max )}$ and absorption of VCR and VLB according to medium pH

\begin{tabular}{|c|c|c|c|c|c|c|c|c|c|c|}
\hline \multirow{2}{*}{$\begin{array}{l}\text { Variation of } \\
\lambda_{\max (\mathrm{nm})}\end{array}$} & \multicolumn{10}{|c|}{ Variation of Abs VLB sulfate $25 \mu \mathrm{g} / \mathrm{ml}$ standard buffer solutions } \\
\hline & Purified water & pH-3 & pH-4 & pH-5 & pH-6 & pH-7 & pH-8 & pH-9 & pH-9.3 & pH-10 \\
\hline 260.5 & - & - & - & - & - & - & - & - & - & $0.394^{* * * *}$ \\
\hline 261 & - & - & - & - & - & - & - & $0.394^{* * *}$ & $0.395^{* * *}$ & - \\
\hline 266.5 & - & - & - & - & - & - & $0.392^{* *}$ & - & - & - \\
\hline 267 & - & - & - & - & - & - & - & - & - & - \\
\hline 267.5 & - & 0.439* & - & - & - & - & - & - & - & - \\
\hline 268 & $0.492^{*}$ & - & $0.452^{*}$ & $0.458^{*}$ & - & - & - & - & - & - \\
\hline 269 & - & - & - & - & $0.448^{*}$ & $0.441^{*}$ & - & - & - & - \\
\hline \multicolumn{11}{|c|}{ Variation of Abs VCR sulfate $25 \mu \mathrm{g} / \mathrm{ml}$ standard buffer solutions } \\
\hline 295 & $0.498 *$ & - & - & - & - & - & - & - & - & - \\
\hline 295.5 & - & $0.421 *$ & - & $0.429 *$ & $0.495^{*}$ & $0.431^{*}$ & - & - & - & - \\
\hline 296 & - & - & $0.415^{*}$ & - & - & - & $0.522^{* *}$ & - & - & - \\
\hline 296.5 & - & - & - & - & - & - & - & - & - & - \\
\hline 297.5 & - & - & - & - & - & - & - & $0.416^{* * *}$ & $0.397^{* * *}$ & $0.43^{* * * *}$ \\
\hline
\end{tabular}

*Total amount of samples (n)-30, All Abs values represent mean \pm SD, [SD-where, ${ }^{*} \pm 0.001,{ }^{* *} \pm 0.002,{ }^{* * *} \pm 0.003, * * * * \pm 0.004$ respectively]

Table 11: Absorption values of VCR and VLB aqueous standard solutions at $\lambda_{(\max )}$

\begin{tabular}{|c|c|c|c|c|c|}
\hline \multirow[t]{3}{*}{ Concentration of VCR $(\mu \mathrm{g} / \mathrm{ml})$} & \multicolumn{2}{|c|}{ Absorption value VCR } & \multicolumn{2}{|c|}{ Absorption value VLB } & \multirow{3}{*}{$\begin{array}{l}\text { Concentration of VLB } \\
(\mu \mathrm{g} / \mathrm{ml})\end{array}$} \\
\hline & \multicolumn{2}{|c|}{$\lambda_{(\max )} \mathbf{n m}$} & \multicolumn{2}{|l|}{$\lambda_{(\max )} \mathrm{nm}$} & \\
\hline & $256 \mathrm{~nm}$ & $295 \mathrm{~nm}$ & $214 \mathrm{~nm}$ & $268 \mathrm{~nm}$ & \\
\hline 5 & $0.114 \pm 0.002$ & $0.109 \pm 0.002$ & $0.313 \pm 0.001$ & $0.105 \pm 0.001$ & 5 \\
\hline 10 & $0.219 \pm 0.001$ & $0.208 \pm 0.001$ & $0.661 \pm 0.001$ & $0.200 \pm 0.001$ & 10 \\
\hline 15 & $0.313 \pm 0.002$ & $0.304 \pm 0.001$ & $1.000 \pm 0.001$ & $0.298 \pm 0.001$ & 15 \\
\hline 20 & $0.413 \pm 0.001$ & $0.405 \pm 0.001$ & $1.360 \pm 0.002$ & $0.403 \pm 0.001$ & 20 \\
\hline 25 & $0.509 \pm 0.001$ & $0.502 \pm 0.001$ & $1.701 \pm 0.001$ & $0.498 \pm 0.001$ & 25 \\
\hline 30 & $0.593 \pm 0.002$ & $0.588 \pm 0.002$ & $2.038 \pm 0.001$ & $0.593 \pm 0.001$ & 30 \\
\hline 35 & $0.697 \pm 0.001$ & $0.694 \pm 0.001$ & $2.396 \pm 0.001$ & $0.681 \pm 0.001$ & 35 \\
\hline 40 & $0.806 \pm 0.002$ & $0.803 \pm 0.002$ & $2.813 \pm 0.002$ & $0.782 \pm 0.002$ & 40 \\
\hline 45 & $0.902 \pm 0.001$ & $0.893 \pm 0.001$ & $3.123 \pm 0.004$ & $0.874 \pm 0.004$ & 45 \\
\hline 50 & $1.004 \pm 0.005$ & $0.984 \pm 0.005$ & $3.319 \pm 0.003$ & $0.971 \pm 0.002$ & 50 \\
\hline 100 & $1.582 \pm 0.005$ & $1.568 \pm 0.005$ & $3.563 \pm 0.005$ & $1.895 \pm 0.005$ & 100 \\
\hline
\end{tabular}

*Total amount of samples (n)-33, All Abs values represent mean \pm SD

Table 12: The ratio of the optical density (Abs) value VCR and VLB aqueous standard solutions in $\lambda_{\text {(max) }}$

\begin{tabular}{ll}
\hline Ratio of $\lambda_{(\max )}$ in analytical range & The ratio value \\
\hline $\operatorname{VCR} \lambda_{(\max )} 256 \mathrm{~nm} / \lambda_{(\max )} 295 \mathrm{~nm}$ & $1.0202 \pm 0.0182$ \\
$\operatorname{VLB} \lambda_{(\max )} 214 \mathrm{~nm} / \lambda_{(\max )} 268 \mathrm{~nm}$ & $3.3067 \pm 0.1778$ \\
\hline
\end{tabular}

All values represent mean \pm SD

The ratio of the optical density (Abs) value at $\lambda$ (max) $295 \mathrm{~nm}$ over $\lambda$ (max) $256 \mathrm{~nm}$ for VCR standard aqueous solutions and at $\lambda(\max ) 268$ $\mathrm{nm}$ over $\lambda_{(\max )} 214 \mathrm{~nm}$ for VLB standard aqueous solution (table. 10) were calculated. The nearly constant ratio values were demonstrating their conformity to the law of Bouguer-LambertBeer's in the analytical range.

\section{DISCUSSION}

The US Pharmacopoeia Convention 2011, recommend using a solution of ammonium formate buffer as a solvent for the spectrophotometric quantitative determination method VCR sulfate for best practices, solvent $\mathrm{pH}$ corresponded to $\mathrm{pH} 5$ and

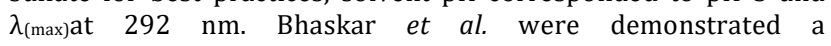

spectrophotometric method for determination and quantity analysis of VLB tableted drug form $\lambda_{(\max )}$ at $420 \mathrm{~nm}$ in the visible range; methanol was used as solvent [35]. Different from that method, in this experiment was established, that the quantitative determination of VCR and VLB sulfate in the substances and dosage forms can use purified water as a solvent. The optimal analytical maximum were $\lambda_{(\max )}-295 \mathrm{~nm}$ and $\lambda_{(\max )}-268 \mathrm{~nm}$ for the VCR and VLB sulfate respectively. Nagaraja et al.[36] were developed the spectrophotometric method for determination VCR and VLB sulfate base on the forming color complex with diazotized dapsone. VCR and VLB were formed yellow azo products with absorption maxima at $430 \mathrm{~nm}$, with ferricyanide in hydrochloric acid medium yield blue products with absorption maxima at $750 \mathrm{~nm}$. The 
major problem of the complex-forming reactions with TIAs had to control a lot of factors to maintains the stability of the formed complex. Nagaraja et al. were demonstrated those color complexes stable for 1 hour; then the analysis procedure has to complete within
1 hour. In here described method no need any additional treatment, chemicals, and reagents for the analysis procedure and aqueous solutions have a long stable period (stable for at least one week without alteration at $4{ }^{\circ} \mathrm{C}$ ).
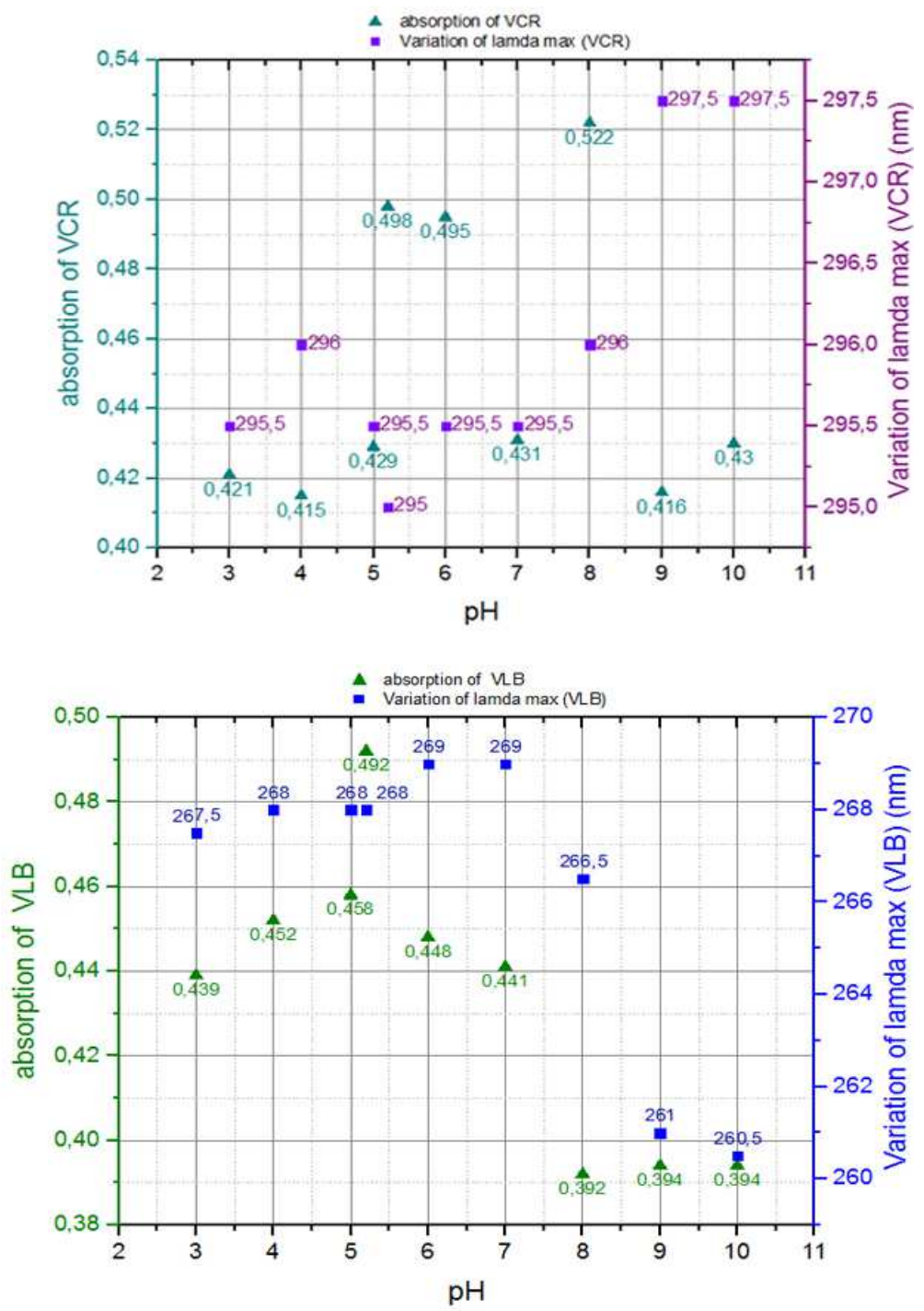

Fig. 7: Variation of $\lambda_{(\max )}$ and absorption VCR and VLB according to medium pH, (graphical demonstration)

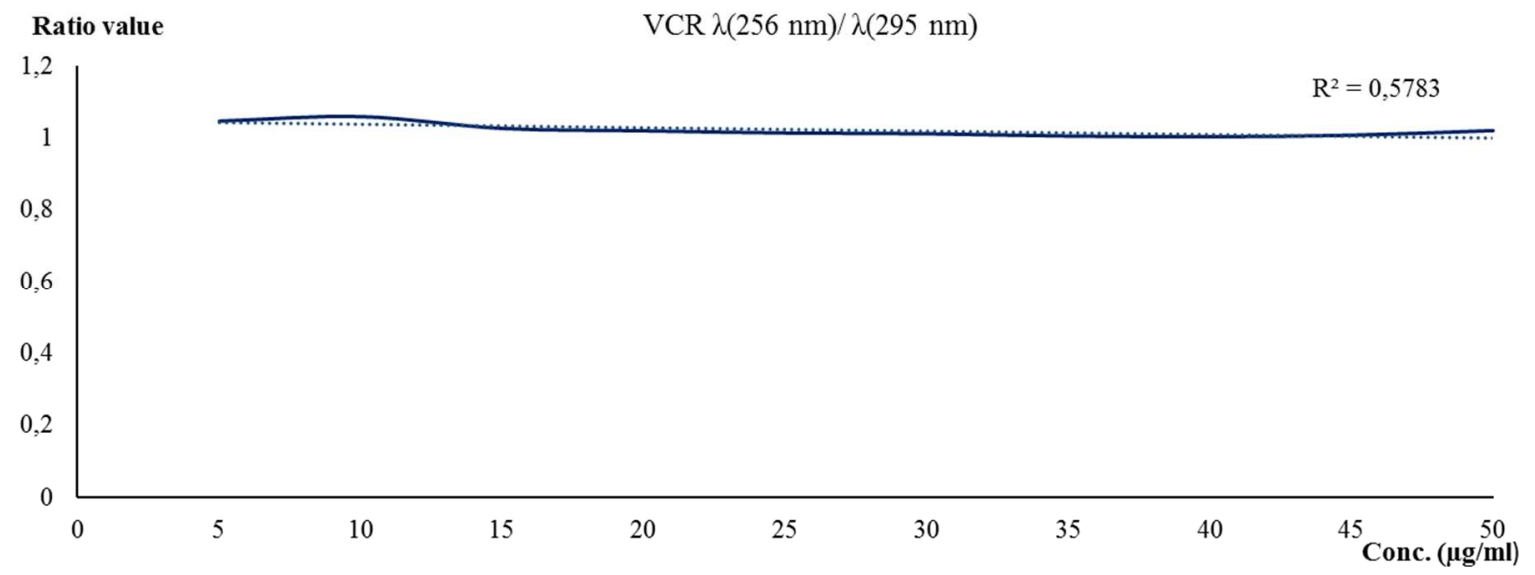

Fig. 8: VCR aqueous standard solutions optical density ratio value in $\lambda_{(\max )} 256 \mathrm{~nm} / 295 \mathrm{~nm}$ 


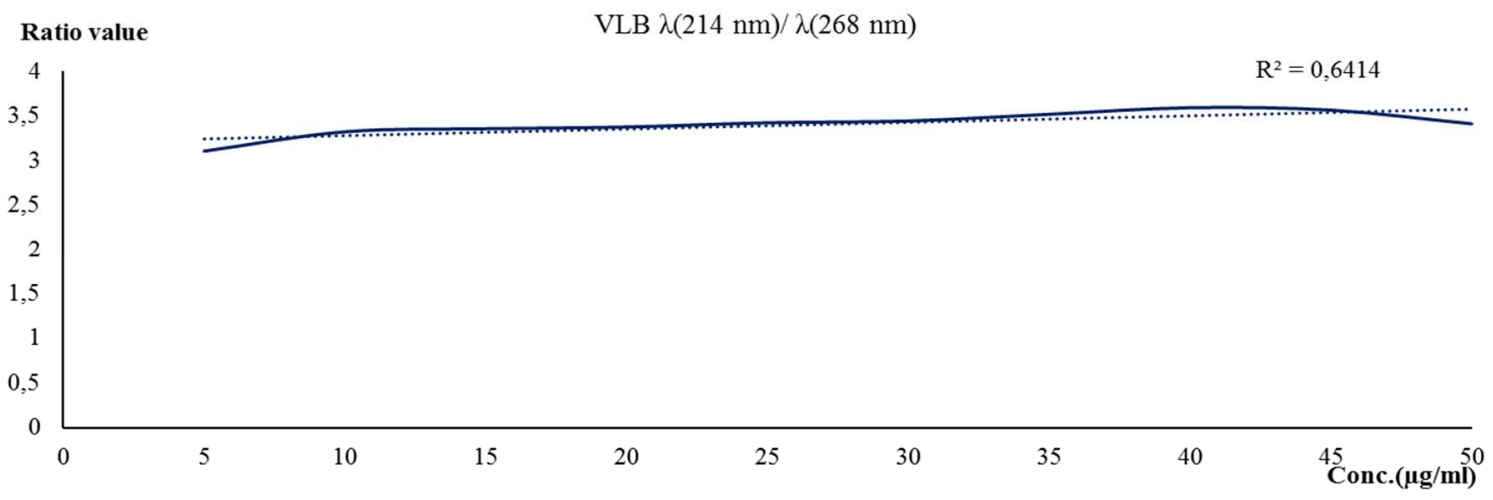

Fig. 9: VLB aqueous standard solutions optical density ratio value in $\lambda_{(\max )} 214 \mathrm{~nm} / 268 \mathrm{~nm}$

The medium $\mathrm{pH}$ changes can impact to the absorption maximum of VCR and VLB. In the more acidic environment was disappearing absorption maximum in the region 190-230 nm, for VCR absorption maximum at $\lambda_{(\max )}-219 \mathrm{~nm}$ and VLB at $\lambda_{(\max )}-214 \mathrm{~nm}$. Also, the absorption maximums in the $230-300 \mathrm{~nm}$ region were changing, the maximum peak shifted to the side of increasing wavelengths (right), and the absorption intensity was decreased. In the experiment was established, using freshly prepared purified water ( $\mathrm{pH}-5.20$ at $\left.20{ }^{\circ} \mathrm{C}\right)$ as a solvent, was the best alternative for the elaborate an analytical method except for methanol or buffer solution recommended in the pharmacopoeial method. The regression equation, standard deviations, correlation coefficient $(r), y=0.0195 x+0.0112,0.00538$, 0.9997 , and $y=0.0192 x+0.0115,0.00438,0.9998$ for VCR sulfate, and VLB sulfate were demonstrated precise linearity in the analytical range. The calculated mean value of absorption ratio, for $\operatorname{VCR} \lambda_{(\max )} 256 \mathrm{~nm} / \lambda_{(\max )} 295 \mathrm{~nm}(1.0202 \pm 0.0182)$, and VLB $\lambda_{(\max )}$ $214 \mathrm{~nm} / \lambda_{(\max )} 268 \mathrm{~nm}(3.3067 \pm 0.1778)$ were testified the purity of the substance and obedience to Bouguer-Lambert-Beer's law in the analytical range $(5-50 \mu \mathrm{g} / \mathrm{ml})$. This information can have used to identify impurities (light-absorbing substances) of the VCR and VLB sulfate in the substance and the dosage forms.

In the validation procedure was established the accuracy (mean \pm SD) of the quantitative determination of the analytical method for VCR sulfate $\sim 100.4 \pm 0.1485 \%$, and VLB sulfate $~ 100.32 \pm 0.1080 \%$ with RSD less than 1\%. Bhaskar et al.[35] were shown in their experiment, the accuracy of the developed analytical method for velban (VLB) $101.97 \pm 0.0031 \%$, and a method was described in this paper has shown pretty decent accuracy according to the Bhaskar $e t$ al. method. The reproducibility and repeatability of the developed method were established by the study of precision for VCR and VLB determined by 27 samples inside and inter-laboratories analyzed, and the RSD was found to be less than $1 \%$. The validated analytical method was applied for Vincristine-TEVA and VERO-vincristine quality assessments and was established those commercial dosage form meets the all the pharmacopeial requirements.

\section{CONCLUSION}

Nowadays for the quantitative analysis of the terpenoid indole drugs group usually appropriate methods were HPLC and its variations, because of those methods have high sensitivity and selectiveness but labor intensiveness, the cost of the instruments and additional chemicals, duration of analysis time and repeatability keep those methods away from regular usage in the clinical laboratories. In this paper was described the application possibility of a simple spectrophotometric method for quality and quantity determination of VCR and VLB in bulk and dosage forms in the UV region. As a solvent was using freshly prepared purified water, and simple analytical procedure were major benefits of this method. The validated analytical method was simple, rapid, reproducible, accurate, precise and cost-effective, can apply for the quality control purposes of substances and as well as for the drugs forms well.

\section{CONFLICT OF INTERESTS}

Declared none

\section{REFERENCES}

1. Avendano C, Menéndez JC. Medicinal chemistry of anticancer drugs. 2nd ed. The Boulevard, UK: Elsevier; 2008.

2. Dennison JB, Jones DR, Renbarger JL, Hall SD. Effect of CYP3A5 expression on vincristine metabolism with human liver microsomes. J Pharmacol Exp Ther 2007;321:553-63.

3. Embree L. Pharmacokinetic behavior of vincristine sulfate following administration of vincristine sulfate liposome injection. Cancer Chemother Pharmacol 1998;41:347-52.

4. Coufal N, Farnaes L. The vinca alkaloids. In: Minev BR. editor. Cancer management in man: chemotherapy, biological therapy, hyperthermia and supporting measures. NY 10605: Springer Dordrecht Heidelberg London New York; 2011. p. 25-38.

5. Greig NH, Soncrant TT, Shetty HU, Momma S, Smith QR, Rapoport SI. Brain uptake and anticancer activities of vincristine and vinblastine are restricted by their low cerebrovascular permeability and binding to plasma constituents in rats. Cancer Chemother Pharmacol 1990;26:263-8.

6. Orekhov AP. Chemistry of alkaloids. 2nd ed. Konovalova RA, Konovalova A. editor. Moscow (M): academy of science USSR; 1955.

7. Volkov SK. Medicinal plants method of analysis of some antitumor-active alkaloids from Catharanthus roseus. Pharm Chem J 1996;30:391-9.

8. Yan Z, Zhu Z, Qian Z, Hu G, Wang H, Liu W, et al. Pharmacokinetic characteristics of vincristine sulfate liposomes in patients with advanced solid tumors. Acta Pharmacol Sin 2012;33:852-8.

9. Almagro L, Fernández-Pérez F, Pedreño M. Indole alkaloids from Catharanthus roseus: bioproduction and their effect on human health. Molecules 2015;20:2973-3000.

10. Nejat N, Valdiani A, Cahill D, Tan YH, Maziah M, Abiri R. Ornamental exterior versus therapeutic interior of Madagascar Periwinkle (Catharanthus roseus): the two faces of a versatile herb. Sci World J 2015:1-19. http://dx.doi.org/10.1155/ 2015/982412

11. Chen Q, Li N, Zhang W, Chen J, Chen Z. Simultaneous determination of vinblastine and its monomeric precursor's vindoline and catharanthine in Catharanthus roseus by capillary electrophoresis-mass spectrometry. J Sep Sci 2011;34:2885-92.

12. O'Connor SE, Maresh JJ. Chemistry and biology of monoterpene indole alkaloid biosynthesis. Nat Prod Rep 2006;23:532-47.

13. Dhayalan M, Anitha Jegadeeshwari L, Nagendra Gandhi N. Biological activity sources from traditionally used tribe and herbal plants material. Asian J Pharm Clin Res 2015;8:11-23.

14. Kaur R, Arora S. Alkaloids-important therapeutic secondary metabolites of plant origin. J Crit Rev 2015;2:1-8.

15. Jakovljevic IM. Colorimetric method for the determination of vinblastine, an alkaloid from Vinca rosea $L$. J Pharm Sci 1962;51:187-8.

16. British Pharmacopoeia, Her Majesty's Stationary Office, London. Vol. I-II. Monographs: electronic version; 2013. 
17. Hisiger S, Jolicoeur M. Analysis of Catharanthus roseus alkaloids by HPLC. Phyto Chem Rev 2007;6:207-34.

18. Sander GW. Quantitative analysis of metabolic pathways in Catharanthus roseus hairy roots metabolically engineered for terpenoid indole alkaloid overproduction [dissertation]. Ames, Iowa(AI): Iowa State University; 2009.

19. Shukla AK, Shasany AK, Gupta MM, Khanuja SPS. Transcriptome analysis in Catharanthus roseus leaves and roots for comparative terpenoid indole alkaloid profiles. J Exp Bot 2006;57:3921-32

20. Chu I, Bodnar JA, White EL, Bowman RN. Quantification of vincristine and vinblastine in Catharanthus roseus plants by capillary zone electrophoresis. J Chromatogr 1996;755:281-8.

21. Van Belle SJ, De Smet M, De Neve W, Monsaert C, Storme GA, Massart, et al. Determination of vinca alkaloids in mouse tissues by high-performance liquid chromatography. J Chromatogr 1992;578:223-9.

22. Volkov SK, Grodnitskaya EI. Application of high-performance liquid chromatography to the determination of vinblastine in Catharanthus roseus. J Chromatogr B 1994;660:405-8.

23. Vendrig DEMM, Holthuis JJM. Trace level analysis of vinca alkaloids in biological fluids. Trends Anal Chem 1989;8:141-5.

24. Vendrig DEMM, Teeuwsen J, Holthuis JJM. Analysis of vinca alkaloids in plasma and urine using high-performance liquid chromatography with electrochemical detection. J Chromatogr Biomed Sci Appl 1988;424:83-94

25. Auriola S, Naaranlahti T, Lapinjoki SP. Determination of Catharanthus roseus alkaloids by high-performance liquid chromatography-isotope dilution thermospray mass spectrometry. J Chromatogr A 1991;554:227-31.

26. Tam MN, Nikolova Damyanova B, Pyuskyulev B. Quantitative thin layer chromatography of indole alkaloids. II. catharanthine and vindoline. J Liq Chromatogr 1995;18:849-58.

27. Zhu J, Lin Q. Determination of vincristine and vinblastine in Catharanthus roses leaves by liquid chromatography-mass spectrometry; 2000. Available from: http://www.albany.edu/ genomics/proteomics/pdf/Presentations/08ASMS.pdf. [Last accessed on 01 Jan 2015].
28. Guo P, Wang X, Zhou F, Gallo JM. Determination of vincristine in mouse plasma and brain tissues by liquid chromatographyelectrospray mass spectrometry. J Chromatogr B 2004;809:273-8.

29. Barthe L, Ribet JP, Pélissou M, Degude MJ, Fahy J, Duflos A. Optimization of the separation of vinca alkaloids by nonaqueous capillary electrophoresis. J Chromatogr A 2002;968:241-50.

30. Sethi VS, Burton SS, Jackson DV. A sensitive radioimmunoassay for vincristine and vinblastine. Cancer Chemother Pharmacol 1980;4:183-7.

31. Lelievre E, Guillaudeux J, Cardona H, Bourguignat A, Lokiec F, Solere P, et al. Human pharmacokinetics of a new vinca alkaloid S 12363 with Use of a monoclonal antibody-based radio-or enzyme immunoassay. Cancer Res 1993;53:3536-40.

32. Yadav N, Goyal A. A validated a spectrophotometric method for determination of vilazodone hydrochloride in pharmaceutical dosage form. Int J Curr Pharm Res 2017;9:132-5.

33. Kesur BR, Salunkhe VR, Magdum CS. Development and validation of UV spectrophotometric method and RP-HPLC method for estimation of capecitabine in bulk and tablet dosage forms. Int J Appl Pharm 2012;4:271-4.

34. Yadav LDS. Organic spectroscopy. Springer-science business media, B. V. Dordrecht: Springer Netherlands; 2005.

35. Bhaskar Reddy CM, Subba Reddy GV. Validated method for vinblastin by spectrophotometry in bulk drug and pharmaceutical formulations. J Chem Pharm Res 2012;4:3703-7.

36. Nagaraja Padmarajaiah, Vasantha Ramanathapura A, Yathirajan Hemmige S. Sensitive and rapid spectrophotometric methods for determination of anticancer drugs. J AOAC Int 2002;85:1021-4.

\section{How to cite this article}

- Halahakoon Amila Jeewantha, Slivkin Aleksei Ivanovich, Karlov Pavel Mihailovich. Validated spectrophotometric method for the estimation of vincristine and vinblastine. Int J Pharm Pharm Sci 2017;9(4):78-86. 